\title{
0 currículo do ensino fundamental como tema de política pública: a cultura como conteúdo central *
}

Vitor Henrique Paro**

\section{Resumo}

Derivado de estudo mais amplo sobre a estrutura da escola pública fundamental, este artigo examina a questão do currículo escolar na perspectiva do direito à escolarização elementar, como preocupação das políticas públicas em educação. A partir da análise de dados colhidos em pesquisa de natureza qualitativa, o texto questiona a estreiteza da atual configuração curricular do ensino fundamental, expressa nas próprias avaliações em larga escala patrocinadas pelas políticas educacionais. Conclui pela necessidade de um conteúdo do ensino que, por razões técnicas e políticas, não pode bastar-se em conhecimentos e informações, mas deve expandir-se para a cultura em sentido pleno, como direito universal, que também inclui valores, filosofia, crenças, direito, arte, tecnologia, tudo enfim que é produzido historicamente e que precisa compor a formação plena de personalidades humano-históricas.

Palavras-chave: Currículo escolar. Ensino fundamental. Políticas educacionais. Direito à educação.

\section{The curriculum of elementary schools as a policy issue: culture as central content Abstract}

Derived from a broader study on the structure of the elementary public school, this article examines the issue of the school curriculum under the perspective of the right to basic education, as a public policy concern in education. Based on data collected in a qualitative research, the article questions the narrowness of the current configuration of the elementary school curriculum, expressed in large-scale assessments sponsored by educational policies. It concludes that it is necessary to

\footnotetext{
* Este trabalho é resultado de pesquisa que teve financiamento parcial do CNPq.

** Professor Titular, Faculdade de Educação, Universidade de São Paulo (FEUSP). E-mail: vhparo@usp.br
} 
establish a content of teaching that, due to technical and political issues, is not enough in knowledge and information, but should also include the culture in its full meaning, as a universal right that also includes values, philosophy, beliefs, law, art, technology, everything, ultimately, that is historically produced and must compose the full construction of human-historical personalities.

Keywords: Curriculum. Elementary school. Educational policies. Right to education.

\section{El plan de estudios de la enseñanza básica como tema de Politica pública: la cultura como contenido central Resumen}

Derivado de un estudio más amplio sobre la estructura de la escuela pública Básica, este artículo analiza el tema del plan de estudios escolar desde la perspectiva del derecho a la educación primaria, como preocupación de las políticas públicas en educación. A partir del análisis de los datos recogidos en investigación de naturaleza cualitativa, este artículo cuestiona la estrechez de la configuración actual del plan de estudios de la enseñanza primaria, expresada en las propias evaluaciones a gran escala patrocinadas por las políticas educacionales. Concluye por la necesidad de un contenido de enseñanza que, por razones técnicas y políticas, no puede limitarse al conocimiento y a la información, sino que debe ampliarse a la cultura en el sentido pleno, como un derecho universal, que también incluye valores, filosofía, creencias, derecho, arte, tecnología, todo, finalmente, lo que se produce históricamente y necesita componer la formación plena de personalidades humano-históricas.

Palabras clave: Plan de estudios escolar. Educación primaria. Políticas educacionales. Derecho a la educación.

\section{Introdução}

0 estudo da estrutura da escola pública fundamental, à luz de um conceito de educação como prática democrática, constituiu objetivo geral de pesquisa de caráter qualitativo, que realizei de março de 2007 a fevereiro de 2010 no sistema estadual paulista de ensino. 0 trabalho de campo foi desenvolvido em escola localizada na capital do estado com oferta de ensino fundamental da primeira à quarta série, durante o ano letivo de 2008. A "estrutura total da escola" (CÂNDIDO, 1974, p. 107) foi entendida de modo mais amplo do que seu emprego vulgar ou do que sua mera conotação formal, de modo que envolvesse um conjunto variado de temas e questões que permitissem tratar de forma mais rigorosa a complexa realidade escolar e os fins a que esta deve servir. No Relatório de Pesquisa (PARO, 2010) estão registrados os resultados completos da investigação. Neste artigo, procuro discutir um desses importantes temas, desenvolvendo análises suscitadas pela pesquisa a respeito das questões curriculares da escola fundamental. 
Em termos de políticas públicas, a relevância do debate a respeito do currículo da escola fundamental parece óbvia, já que toda política educacional só ganha sentido se estiver referida àquilo que deve ser seu propósito por excelência, ou seja, o provimento, aos educandos, de um conteúdo cultural que Ihes proporcione formar-se como cidadãos. No entanto, esse debate parece não ter conseguido ainda a força social e política suficiente para questionar radicalmente a estrutura curricular de nossas escolas, de modo a buscar medidas que visem a superá-la. 0 currículo da escola fundamental tem permanecido com a mesma configuração há muitas décadas, mantendo sua forma verbalista e restringindo seu conteúdo às disciplinas tradicionais, adstritas a conhecimentos e informações. A sociedade mudou, novos direitos políticos, civis e sociais foram alcançados ou entraram na pauta de reivindicações, mas a concepção de currículo e daquilo que é necessário para a formação humano-histórica dos cidadãos continua a mesma.

Apesar disso, especialmente nos últimos anos, tanto as políticas públicas quanto boa parte da academia parecem dar pouca atenção à importância do currículo para a efetiva qualidade do ensino, preferindo pautar suas iniciativas e análises quase exclusivamente nos resultados das avaliações em massa, que privilegiam a aferição de conhecimentos "adquiridos", sem grande atenção para a cultura em seu sentido pleno. E este, me parece, é mais um fator que reforça a relevância de se problematizar a atual estrutura curricular da escola fundamental, em razão dos subsídios que esse questionamento pode oferecer para uma melhor adequação da própria maneira como o Estado procura avaliar a qualidade do ensino. Independentemente do real poder das avaliações externas para aferir a aquisição de conhecimentos, será que seus resultados podem servir de parâmetros para indicar até que ponto o Estado está atendendo ao direito das pessoas à cultura, visto que esta, em seu sentido pleno, não é contemplada em tais medições?

Tal discussão deve iniciar-se pela constatação de que o currículo é um dos aspectos que mostram mais enfaticamente como a escola tradicional tem privilegiado uma dimensão "conteudista" do ensino, que enxerga a instituição escolar como mera transmissora de conhecimentos e informações. Daí a relevância de se pensar em sua reformulação numa perspectiva mais ampla que contemple a formação integral do educando. Certamente, não se pode contestar a importância dos conteúdos das disciplinas tradicionais (Matemática, Geografia, História, Ciências etc.), que são imprescindiveis para a formação humana e não podem, sob nenhum pretexto, ser minimizados. Todavia, conteúdos como a dança, a música, as artes plásticas e outras manifestações da cultura são igualmente necessários para o usufruto de uma vida plena de realização pessoal.

As questões relacionadas com a ética, a política, a arte, 0 cuidado pessoal, o uso do corpo e tantos outros temas relacionados ao viver bem das pessoas e grupos não podem constituir apenas "temas transversais" a compor versões escritas de currículos, mas transformar-se em temas centrais na prática diária das escolas (PARO, 2007, p. 113-114). 
Essas matérias que envolvem o uso do corpo, a criatividade, o manuseio de objetos concretos, opiniões individuais, posturas diante de valores, enfim, matérias que levam os educandos a se comportarem mais explicitamente como sujeitos, são importantes não apenas por seu valor intrínseco de componentes da cultura que precisam ser apropriados, mas também porque elas tendem a tornar mais interessantes as demais matérias, especialmente quando com estas se inter-relacionam, tornando o aprendizado mais prazeroso e levando os estudantes a assumirem o estudo de todos os conteúdos como algo que enriquece suas vidas e faz parte constitutiva de seu cotidiano. Por isso, ao se propor a oferecer tão pouco (conhecimentos e informações), a escola tradicional nem esse pouco consegue transmitir. É que as informações e os conhecimentos usualmente só ganham interesse por parte do educando se estiverem no contexto de toda a cultura. Não se pode esquecer que os valores (querer aprender, por exemplo) são componentes culturais.

Quando se trata das questões de currículo não convém nunca deixar de associar conteúdo e forma de ensinar. Se a condição para o educando aprender é que ele seja sujeito, então, por mais abstrato e complexo que seja determinado conteúdo cultural (conhecimento, valor, arte etc.), o aluno só aceita o convite do educador para apropriar-se dele, se se fizer autor, ou seja, ele só aprende na forma de quem age orientado por sua vontade. E isto não é uma questão apenas teórica, mas prática. Corolário disso é que o educador também não pode ser um mero repetidor de conteúdos, mas deve buscar a forma mais adequada para criar no educando a vontade de aprender. É nisso que tem investido toda a Didática, historicamente: criar métodos, técnicas, procedimentos, que produzam no aluno a vontade de aprender. Essa questão da associação entre forma de ensinar e conteúdo que se ensina se torna ainda mais proeminente, quando não se trata apenas de conhecimentos a serem adquiridos, mas de valores e posturas a serem assumidos. Não se pode, por exemplo, ensinar democracia com base em formas autoritárias de ensinar. É nessas situações que mais claramente se percebe que, em educação, a forma é conteúdo.

Quando se fala de formas de ensinar que favoreçam a vontade de estudar do educando, é bom não se esquecer que esse princípio não se restringe a uma relação entre professor e aluno dentro de uma sala de aula. É a escola inteira que deve ser motivadora; portanto, é a escola toda que deve se tornar educadora. A esse respeito, o enriquecimento do currículo não pode se restringir a mero acréscimo de disciplinas a serem estudadas, mas a uma verdadeira transformação da escola num lugar desejável pelo aluno, onde ele não vá apenas para se preparar para a vida, mas para vivê-la efetivamente. Assim, ele não é mero "cliente" de uma sala de aula, mas cidadão de toda uma escola que lhe propicia condições de participar de variadas atividades, no grupo de dança, no coral, no clube de ciências, no conjunto musical, no grupo de teatro, na roda de capoeira etc. etc.

Assim concebida, a escola é um lugar que deve fazer parte da vida das crianças, não provocar sua negação. Não deixa de ser desalentador perceber o quanto nossa escola 
tradicional tem negado esse principio. Basta contemplar o mito de que ensino não se pode misturar com brincadeira, bastante presente no imaginário de nossos professores da escola fundamental, para se ter a dimensão dessa verdadeira negação da escola como local onde se constroem personalidades humano-históricas. Esse mito se sintetiza no esforço que às vezes se percebe em professores do primeiro ano do ensino fundamental que, desde o primeiro dia de aula, procuram convencer as crianças vindas da escola de educação infantil de que a escola, diferentemente da pré-escola, não é lugar de brincar, mas de estudar [...] (PARO, 2003). Imagine-se a situação de crianças pequenas - para quem a alegria de viver se resume, em boa parte, em brincar - ver-se privada disso. Como é possivel ensinar para alunos cuja forma privilegiada de se fazer sujeito é o brincar, se se thes proibe essa atividade? É como se fosse possivel aprender sem ser sujeito. É como se vivêssemos um tempo em que a Didática ainda não tivesse descoberto a importância do lúdico na aprendizagem. Hoje, com o avanço dos conhecimentos na Pedagogia, continuar repelindo a brincadeira como adversária do ensino implica cortar pela raiz a possibilidade de fazer da escola uma verdadeira casa de educação, o que aponta mais uma vez para a relevância de se estudarem alternativas de transformação do currículo da escola fundamental, tanto no conteúdo quanto na forma.

\section{A cultura como matéria-prima do currículo}

Falar do currículo da escola fundamental é falar do conteúdo do ensino, mas de uma forma mais ampla do que usualmente se entende. Os "conteudistas" reduzem o conteúdo aos conhecimentos e informações que são transmitidos pela escola. Todavia, se educação é formação de personalidades humano-históricas, o seu conteúdo tem a ver com a cultura em seu sentido pleno: conhecimentos, informações, valores, crenças, tecnologia, ciência, arte, filosofia, direito etc., ou seja, tudo aquilo que é criado pelos homens, por contraposição à natureza, que existe independentemente de sua ação e vontade. De acordo com Alfred North Whitehead (1969, p. 13), "fragmentos de informações nada têm a ver com [cultura]. Um homem meramente bem informado é o maçante mais inútil na face da terra."

0 conceito de cultura, nesse sentido mais amplo, tem relação com o significado que Ihe dá, por exemplo, Lourenço Filho (2002, p. 198, grifos do autor), para quem,

a palavra cultura [...] designa a soma total das criações humanas, ou o resultado organizado da experiência de um grupo qualquer, num dado momento ou momentos sucessivos. Inclui instrumentos, habitações, armas, todos os bens de produção existentes no grupo, como os processos de sua utilização; e ainda tudo quanto esse grupo tenha elaborado na forma de atitudes e crenças, ideias e opiniões, códigos e instruções, arte e ciência, organização social e filosofia de vida. Uma cultura se constitui, pelo que se vê, de elementos materiais, e não materiais, ou simbólicos. 
A primeira consequência da consideração da cultura como conteúdo do ensino é que a estrutura curricular está necessariamente associada à estrutura didática. $\mathrm{Ou}$ seja, o primeiro conteúdo do currículo é precisamente a forma de ensinar, visto ser no contexto da cultura que se forjam os conhecimentos, técnicas, objetos e valores presentes na "relação" pedagógica. Nessa perspectiva, ao se tratar da estrutura didática, na verdade, está-se falando sobre um dos componentes da estrutura curricular. Ao educar-se, o estudante, ao lado de todos os demais elementos da cultura (conhecimentos, valores etc.), incorpora os valores que dão forma à maneira de essa cultura ser passada, pela simples razão de os valores não serem passados apenas por palavras, regras ou recomendações, mas principalmente pela conduta assumida na relação.

A relação pedagógica, para fazer-se eficientemente, exige uma forma democrática de relacionamento. Mas, ao fazer-se conteúdo do ensino, essa forma não é assimilada pelo educando apenas como forma de ensinar e aprender. Para, além disso, em sua personalidade vão-se incorporando valores de cunho universal relacionados à forma democrática de convivência entre humanos, ou melhor, entre cidadãos. Como se vê, esse componente político' presente na educação como prática democrática é ingrediente curricular fundamental na formação de personalidades livres e autônomas.

Lamentavelmente, esse componente não tem recebido a devida atenção por parte das políticas públicas em educação. Se fosse valorizado, a primeira questão que viria à tona aos formuladores de currículos e programas para o ensino fundamental seria a consideração do caráter democrático da personalidade do educador escolar, especialmente do professor, e de sua capacidade de exercitar essa condição na interação com o educando. A importância desse fator decorre do fato de que a transmissão de valores - e das condutas que eles favorecem - não se sustenta em palavras e preceitos, como comumente se supõe. A relação pedagógica como relação entre sujeitos supõe que o educando, para aprender, seja levado a aplicar sua vontade, como autor, no processo de aprendizado; e que o educador, para ensinar, seja "verdadeiro" na transmissão de determinado componente cultural, ou seja, que ele reconheça e aceite o valor desse elemento e, como sujeito, aplique sua vontade na transmissão de tal elemento. Esta é uma condição necessária para que o educador possa levar o educando a fazer-se sujeito e aprender. Em consequência, para dar conta da passagem da democracia como componente curricular, é preciso que o educador "queira" ser democrático e "seja capaz de agir" democraticamente.

Acontece que a formação dessa "personalidade democrática" do educador escolar não se faz inteiramente por meio dos livros e dos cursos de Pedagogia e outros de formação de professores. 0 essencial dessa formação é constituído muito antes de 0 jovem chegar ao ensino superior, sendo de particular importância o tipo de educação

1 Tomo o conceito de política em seu sentido geral de "atividade humano-social com o propósito de tornar possível a convivência entre grupos e pessoas, na produção da própria existência em sociedade” (PARO, 2002, p. 15).

Ensaio: aval. pol. públ. Educ., Rio de Janeiro, v. 19, n. 72, p. 485-508, jul./set. 2011 
que ele recebe durante o ensino fundamental. Aqui, em pleno período de seu desenvolvimento biopsíquico, o indivíduo é exposto a relações sociais que marcam, indelevelmente, sua personalidade. As crenças, os valores, as visões de mundo e os modos de conduta incorporados durante os primeiros períodos de vida muito dificilmente serão apagados ou substituídos na idade adulta. É por isso que o professor do ensino fundamental de hoje, em geral, é muito mais um replicador das relações pelas quais ele passou no ensino fundamental do que aplicador dos conhecimentos, princípios e métodos com que teve contato em sua formação docente. Assim, se levarmos em conta o caráter autoritário das relações vigentes na escola que esse professor frequentou quando jovem, não é difícil imaginar sua conduta de hoje com seus alunos. Johann Friedrich Herbart (2003), em sua Pedagogia geral, denota rara intuição ao identificar esse processo. Ao mencionar a comum dissociação entre a intenção e 0 êxito em educação, acrescenta um caso que nega essa dissociação, dizendo:

Às vezes, é claro, [a intenção e o êxito] correspondem-se de tal maneira que a pessoa que recebeu a educação se coloca mais tarde na vida no lugar do seu educador, fazendo sofrer os seus educandos precisamente aquilo por que ele passou. 0 modo de pensar é aqui o mesmo que na juventude e que foi formado pela experiência quotidiana, com a diferença de que o lugar incômodo foi trocado pelo mais cômodo. Aprende-se a dominar, obedecendo. Já as crianças pequenas tratam as suas bonecas exatamente da mesma maneira como são tratadas (HERBART, 2003, p. 17-18; grifos nossos).

Em estudo que verifica as razões do apego de educadores ao emprego da reprovação escolar, Vitor Henrique Paro (2003, p. 88-98) constata a força da escolaridade pregressa em professores do ensino fundamental, por meio daquilo que denomina "determinantes psicobiográficos" da propensão à reprovação. Verifica, então, como um ensino de caráter punitivo e que desconsidera a subjetividade do educando "parece levar os professores de hoje a reproduzirem, com seus alunos, a forma como foram tratados, quando estudantes, por seus mestres" (PARO, 2003, p. 89).

A importância determinante, para a educação, dos atributos políticos (autoritários ou democráticos) incorporados na personalidade de cada professor do ensino fundamental deve levar à constatação de que tais atributos, de uma forma ou de outra, são parte integrante do currículo escolar. E a estratégia adequada para dotar o ensino de bons professores no que diz respeito a esse quesito não pode restringir-se à melhoria da formação profissional nos cursos superiores de Pedagogia e assemelhados, porque o mais determinante dessa "formação" já se deu quando o futuro professor frequentava a escola fundamental. Em vista disso, para as gerações futuras cumpre melhorar a educação que é oferecida hoje em nossas escolas fundamentais, porque é ai que, predominantemente, se pode formar a personalidade democrática dos professores de 
amanhã. Mas para as gerações atuais, tanto quanto para a melhoria dessa educação visando a gerações futuras, o caminho mais curto é a formação em serviço das dezenas de milhares de professores que hoje operam no ensino fundamental.

Uma formação em serviço que logre produzir mudanças consistentes nas condutas políticas dos professores de hoje, de modo a tocarem em suas próprias personalidades, precisa superar a atual maneira pontual e anárquica que tem preponderado nos "programas" de formação em serviço e "formações a distância" vigentes. Para isso, é preciso que a estrutura mesma da escola seja transformada, de modo a incluir em sua prática cotidiana momentos de estudo, de leitura, de discussão, de trocas de experiências e de práticas coletivas, visando à melhoria da prática pedagógica.

Ao enfatizar a importância da forma em sua dimensão de conteúdo do currículo escolar, não se está querendo dizer que os conhecimentos e informações constantes das disciplinas escolares não sejam importantes. Ao contrário, eles são tão importantes que é preciso providenciar uma forma de os ensinar que produza sua real apropriação.

Mas, além dessa preocupação com uma forma de ensino que provoque sua efetiva realização, outro aspecto relacionado aos conhecimentos incluídos no currículo escolar refere-se à natureza mesma desses conhecimentos. A esse respeito, é comum ouvir-se falar da necessidade de um conteúdo do ensino que seja crítico e que favoreça a consciência política dos educandos. Não há dúvida de que o conhecimento deve ser crítico, se com este termo estivermos entendendo a superação de uma visão ingênua do mundo. Neste sentido, é crítico todo conhecimento que esteja comprometido com a verdade. Isto vai contra a crença de que a forma por excelência de o ensino se fazer crítico é selecionando os conhecimentos que tragam explicitamente uma intenção política de conscientização. Segundo esse ponto de vista, o caráter crítico do ensino estaria presente apenas naquelas disciplinas que veiculam explicitamente valores ou posturas políticas, como a história, a sociologia e outras disciplinas do campo das ciências humanas. Muito embora não se possa menosprezar a importância dessas disciplinas - e não se deva descartar determinado conteúdo curricular por ele ser explicitamente político -: 0 componente crítico deve estar presente não apenas em todo conhecimento veiculado pelas disciplinas, mas também em toda cultura que venha a compor o currículo escolar.

Por mais "neutra" que possa parecer uma disciplina como a Matemática, por exemplo, não é enxertando questões sociais nos exemplos de problemas matemáticos, como muitos acreditam, que se propiciará um aprendizado mais crítico. A Matemática continuará contribuindo para inibir o espírito crítico se continuar sendo ensinada de maneira "bancária" (FREIRE, 1975), em que as regras e algoritmos são memorizadas sem nenhum questionamento ou descoberta por parte do educando, ou seja, se os conhecimentos forem apenas "revelados" pelo professor, e aceitos passivamente pelo aluno. É preciso precaver-se contra aquilo que Whitehead chama de "ideias iner- 
tes", isto é, "ideias que são simplesmente recebidas pela mente sem que sejam utilizadas ou testadas ou mergulhadas em novas combinações" (WHITEHEAD, 1969, p. 13). A criança que hoje é levada a aceitar passivamente um algoritmo ou uma regra sem compreender seu funcionamento, com base apenas na autoridade do professor ou da escola, tenderá a ser o mesmo indivíduo que, na vida adulta, aceitará preconceitos e injustiças sociais, também passivamente, sem perguntar seu significado e razão de ser.

Michel Lobrot (1977, p. 107), em sua crítica à escola, afirma que esta "não exerce quase nenhuma influência no saber e na capacidade dos adultos pois tudo o que ensina é em grande parte esquecido", mas considera que ela "pode desviar definitivamente o jovem de toda pesquisa intelectual, de toda curiosidade, de toda colaboração efetiva com os outros, se ela instila um fastio insuperável e mantém uma mentalidade de competição e de respeito formal aos mestres".

0 cuidado com a formação do jovem, de modo a que ele não se torne, quando adulto, um simples repetidor de "conteúdos" (leia-se: conhecimentos e informações) é uma preocupação que sempre esteve presente na História da Educação. Tal cuidado estava presente até mesmo no método dos jesuitas que, apesar de não contar com os avanços atuais da Pedagogia, já enfatizava a importância da formação, pela escola, de indivíduos que não fossem meros acúmulos de conhecimentos, mas que soubessem refletir e apreciar a cultura. 0 padre Leonel Franca (1952, p. 83-84), um de seus defensores, assim se manifesta a respeito dessa questão, interpretando o modo de pensar da Ratio Studiorum:

Os conhecimentos positivos de geografia ou de física poderão estar antiquados no cabo de poucos lustros; o raciocínio seguro, o critério na apreciação dos homens, a capacidade de expressão exata, bela e enérgica de uma alma harmoniosamente desenvolvida representam aquisições humanas de valor perene.

Entre nós, entretanto, o que chama a atenção é precisamente a ausência dessa preocupação por parte das políticas públicas. Nossos currículos parecem constituir um enorme rol de conhecimentos a serem armazenados nas cabeças dos estudantes. A esse respeito, as palavras de George Gudsdorf (1987, p. 37, grifo nosso) são bastante atuais e, apesar de se referirem ao sistema francês na década de 1960, aplicam-se sob medida ao Brasil de hoje:

[...] a partir da idade de 6 anos, quando se inicia seriamente a aprendizagem da leitura e da escrita, a criança francesa torna-se a presa de um sistema cujo único ideal é empanturrar cérebros sem levar em conta o essencial desenvolvimento equilibrado da personalidade. Os únicos elemen- 
tos importantes da vida escolar são os programas, as notas, os exercícios, as classificações e, coroando tudo isso, os exames. Tanto que todo o ensino francês parece se reduzir a um gigantesco empreendimento de alienação mental.

Nos dias atuais tornou-se quase sagrado o mito da "sociedade do conhecimento" e da necessidade de adequar-se a ela. A estratégia preferida para proceder a essa adequação parece ser a aquisição da maior quantidade possivel de informação. A reflexão, a criatividade, o espírito crítico, a capacidade de raciocínio e a aptidão para o julgamento são relegados a um plano inferior, e a escola passa a ser valorizada quase só na medida de sua capacidade de fornecer informações. A crítica a essa preocupação apenas com a chamada "instrução", em detrimento do cuidado com a formação integral do cidadão, pode ser feita por meio das palavras lúcidas de Carneiro Leão (1953). Após afirmar que "nada retrata melhor um povo do que seu sistema de educação", e de que "o modo de ser de cada época influi na organização dos sistemas educacionais de cada povo" (LEÃO, 1953, p. 205), ele afirma:

Tais conclusões desautorizariam, se os fatos já se não tivessem encarregado de fazê-lo, a afirmativa de que a instrução é a grande panaceia universal. Afirmou-se por muito tempo: abrir escolas é fechar prisões. Se perguntássemos, porém, quantas prisões as escolas fecharam, nenhuma estatística seria capaz de dizê-lo. A alfabetização pura e simples nada tem feito de construtivo. Se todos os que aprendessem a ler atendessem a seus interesses vitais, obtivessem adaptação a seu meio social e não lessem senão ideias construtoras, a alfabetização só por si seria um programa excelente. De nada vale, entretanto, se os espíritos continuam virgens, se se guardam intactos em sua feição primitiva. Alfabetizar o indivíduo sem fazê-lo crescer, aperfeiçoar-se individualmente, ter consciência de seu papel social, de seus deveres, de seus direitos, de suas responsabilidades e de suas obrigações, na comunidade e para a comunidade, é dar-lhe um instrumento cuja prática pode ser mais prejudicial do que benéfica.

A adoção de uma concepção de currículo que não se baste no rol de conhecimentos a serem transmitidos, mas que contemple também as demais dimensões da cultura, implica considerar pelo menos três tipos de providências relativas a sua concretização: uma seleção de conteúdos, uma articulação entre os vários tipos de conteúdos e uma adequação estrutural da escola com vistas a essa nova concepção de currículo.

No primeiro caso, há que se selecionar, por um lado, os conhecimentos relevantes, nas diversas áreas do saber e das ciências, que comporão as matérias ou disciplinas escolares (Matemática, Língua Portuguesa, História, Filosofia etc.) e, por outro, os novos componentes curriculares relacionados à arte (música, dança, teatro, artes plásticas 
etc.), ao artesanato, ao folclore, ao esporte, ao domínio do corpo, à saúde etc. Certamente, o princípio prevalecente nessas escolhas deve ser o da busca de uma síntese possivel do conteúdo de cada área, e uma ordenação que leve em conta cada fase ou ciclo de desenvolvimento curricular, de modo a propiciar condições de novos avanços e aprofundamentos em cada conteúdo nos estágios e níveis subsequentes do ensino. Além disso, embora se possa (ou se deva) estabelecer mínimos curriculares ou parâmetros orientadores que tenham validade nacional, é preciso garantir a flexibilidade suficiente para permitir os necessários ajustes às características regionais e estimular a criatividade de cada unidade escolar. Quanto a isso, convém ter sempre presente que, como afirma Whitehead (1969, p. 26), "a escola é a verdadeira unidade educacional em qualquer sistema nacional para a salvaguarda da eficiência". Nas palavras do mesmo autor,

cada escola deve ter a prerrogativa de ser considerada em relação a suas circunstâncias especiais. A classificação das escolas para determinadas finalidades é necessária; mas não deveria ser permitido o currículo inteiramente rígido, não modificado por seu próprio corpo docente (WHITEHEAD, 1969, p. 26).

A segunda medida relativa ao dimensionamento curricular diz respeito à imprescindível conexão dos conteúdos das chamadas disciplinas teóricas com os conteúdos relacionados às outras dimensões da cultura que farão parte do currículo. As ciências, as artes e a cultura em geral comportam divisões em disciplinas ou áreas, não para estas se fazerem estanques e independentes umas das outras, mas para facilitar o tratamento específico naquilo que Ihes convém, concorrendo assim para o benefício do todo cultural de que fazem parte. Por isso, também o currículo deve levar em conta essa condição. É preciso não se esquecer que, quando se advoga a superação do atual currículo fundado apenas em conhecimentos e informações, e se propõe a abordagem plena da cultura, uma das reivindicações é precisamente fazer com que essas outras dimensões da cultura deem mais sentido à escola, propiciando maior prazer e satisfação na apropriação dos conhecimentos. Para que isso aconteça, como afirmei no início deste artigo, é preciso que haja inter-relacionamento entre os vários conteúdos, de modo que os vários componentes culturais propiciem aquilo que é próprio de uma educação verdadeiramente significativa: ser intrinsecamente interessante, enriquecer a vida presente do educando, enquanto forma sua personalidade e prepara para futuros enriquecimentos culturais.

Finalmente, o terceiro tipo de providência que deve acompanhar uma reforma curricular refere-se à reestruturação da própria unidade escolar e de seu desenrolar cotidiano. A imensa maioria das escolas são concebidas para receber turmas de alunos ouvintes, em salas separadas. Uma nova concepção de currículo que se preocupe com toda a cultura certamente exigirá uma outra escola, com funções, espaços, tempos e equipamentos completamente diversificados. Neste quesito também não se deve homogeneizar, mas propiciar condições para que cada unidade escolar encontre a melhor forma de dispor seus recursos e adequá-los ao currículo adotado e à população usuária. 


\section{0 direito à cultura}

Tomar a educação como apropriação da cultura traz importantes consequências para a apreciação dos direitos humanos. Em geral costuma-se valorizar o ensino escolar, em particular o fundamental, pelo que ele pode trazer de contribuição ao desenvolvimento econômico e social do país e para a preparação individual dos cidadãos. Esta preparação é usualmente associada aos conhecimentos mínimos necessários para o indivíduo viver em sociedade, para seguir nos níveis subsequentes de ensino e para tornar-se apto ao trabalho (ou melhor, ao emprego). Como geralmente não se adota uma concepção de educação como apropriação da cultura, o direito ao ensino fundamental é visto apenas em termos do cumprimento dessas metas, sem nenhuma referência à cultura plena como direito.

Todavia, entendida a cultura como toda a criação humana (contraposta, portanto, ao mundo natural, que independe da ação e da vontade do homem), é pela apropriação dessa cultura (pela educação), que o homem se diferencia da mera natureza e se faz humano, ou melhor, humano-histórico. 0 direito à cultura significa, portanto, o direito à própria humanização do indivíduo. Segundo Antonio Cândido de Mello e Souza (2004, p. 144), humanização pode ser entendida como

o processo que confirma no homem aqueles traços que reputamos essenciais, como o exercício da reflexão, a aquisição do saber, a boa disposição para com o próximo, o afinamento das emoções, a capacidade de penetrar nos problemas da vida, o senso da beleza, a percepção da complexidade do mundo e dos seres, o cultivo do humor.

Ora, todas essas são qualidades que nos são dadas pela educação como apropriação da cultura. No nascimento, somos mera natureza, quer nasçamos no barraco da favela, embaixo de uma ponte ou na mansão de algum magnata. Fazemo-nos humanos à medida que nos apropriamos da cultura, de tudo o que nossos antepassados, ao fazerem a história, nos deixaram por herança (não genética, mas histórica). Do ponto de vista dos valores democráticos, não há nenhuma razão, portanto, para que essa herança cultural seja distribuida de modo desigual aos cidadãos. Sabemos, porém, que lamentavelmente é precisamente isso que acontece: a cultura é distribuída de acordo com a origem social dos indivíduos, os mais ricos tendo a sua disposição os meios e recursos que lhes possibilitam o desenvolvimento de suas potencialidades, os mais pobres tendo que permanecer à beira da necessidade natural por Ihes serem negadas as condições objetivas de se desenvolverem culturamente.

0 ser humano, para realizar-se como tal, para sentir-se bem, liberto dos griIhões da necessidade, não precisa apenas de conhecimentos e informações. A cultura, na forma de todo desenvolvimento científico, filosófico, ético, artístico, tecno- 
lógico etc., é o próprio substrato da liberdade do homem, para além da necessidade natural. Nesse sentido, cada indivíduo se faz mais livre à medida que se apropria da cultura. Quando falamos de direito à educação, portanto, isso não pode significar o direito apenas a pequenos "pedaços" da cultura, na forma das chamadas disciplinas escolares (Matemática, Geografia, Língua Portuguesa, etc.). Estas são, sem dúvida, partes importantíssimas da herança cultural, mas não são tudo.

A realização pessoal exige muito mais do que fragmentos de cultura que nossa escola se propõe a fornecer. Ela clama por uma educação que logre preparar o indivíduo para o usufruto de todos os bens espirituais e materiais criados historicamente no contexto da cultura, a que todos os cidadãos, pelo fato mesmo de serem cidadãos, têm o direito de acesso. Por isso, numa sociedade verdadeiramente democrática, pautada por valores progressistas de afirmação da condição de sujeito de todos os cidadãos, a cultura não pode ser considerada um bem privado a que apenas os privilegiados das camadas mais abastadas têm acesso, na forma da assim chamada "cultura erudita", destinando aos desprotegidos as migalhas dos conhecimentos escolares.

Todavia, essa visão da cultura como necessidade (e direito) universal ainda está longe de se generalizar em nossa sociedade. Mesmo as pessoas que têm maior acesso à cultura muito raramente percebem essa dimensão dos direitos humanos. Quanto a isso, é preciso estar alerta para o fato de que

pensar em direitos humanos tem um pressuposto: reconhecer que aquilo que consideramos indispensável para nós é também indispensável para o próximo. Essa me parece a essência do problema, inclusive no plano estritamente individual, pois é necessário um grande esforço de educação e autoeducação a fim de reconhecermos sinceramente este postulado. Na verdade, a tendência mais funda é achar que nossos direitos são mais urgentes que os do próximo (MELLO E SOUZA, 2004, p. 134).

A seguir, em sua defesa do direito à literatura, Mello e Souza (2004, p. 134-135) apresenta argumentos que claramente podem se estender para todo o domínio da cultura:

Nesse ponto as pessoas são frequentemente vítimas de uma curiosa obnubilação. Elas afirmam que o próximo tem direito, sem dúvida, a certos bens fundamentais, como casa, comida, instrução, saúde; coisas que ninguém bem formado admite hoje em dia que sejam privilégio de minorias, como são no Brasil. Mas será que pensam que seu semeIhante pobre teria direito a ler Dostoievski ou ouvir os quartetos de Beethoven? Apesar das boas intenções no outro setor, talvez isto não lhes passe pela cabeça. E não por mal, 
mas somente porque quando arrolam seus direitos não estendem todos eles ao semelhante. Ora, o esforço para incluir o semelhante no mesmo elenco de bens que reivindicamos está na base da reflexão sobre os direitos humanos.

Considerando o caráter imprescindivel da cultura para a formação integral da personalidade e para o efetivo exercício da cidadania, o currículo da escola fundamental não pode restringir-se a uma lista de conhecimentos e informações, sonegando aos educandos outros elementos culturais igualmente valiosos. Como vimos até aqui, sonegar a cultura é sonegar uma parte da capacidade de viver em liberdade. Mello e Souza (2004, p. 151) afirma que "negar a fruição da literatura é mutilar a nossa humanidade". Parafraseandoo, podemos dizer que negar a fruição da cultura é negar a nossa humanidade.

\section{Os educadores escolares e o currículo}

Qualquer projeto de mudança na estrutura curricular do ensino fundamental precisa partir da realidade atual de nossas escolas. Um quesito importante dessa tarefa é saber o que pensam os professores e demais educadores escolares. A esse respeito a pesquisa de campo procurou identificar entre os depoentes suas concepções de currículo, suas apreciações relativas à atual estrutura curricular, bem como suas perspectivas em relação à eventual transformação dessa realidade. Neste tópico procuro apresentar o ponto de vista dos entrevistados a respeito desses temas. De um modo geral, as questões levantadas e as opiniões dos educadores parecem representar, em alguma medida, as visões a respeito de currículo comumente presentes na realidade educacional brasileira.

Uma questão que aparece quando se menciona a necessidade de um currículo mais rico para o ensino fundamental, é a que se refere à necessidade da inclusão da política no conteúdo escolar. Vanessa ${ }^{2}$, professora da segunda série, quando perguntada sobre o assunto diz, incontinenti, que é favorável a que se ensine e se discuta política com os alunos:

Eu acho que as crianças desde pequenas já têm que entender certas coisas, até para poder opinar. Eu procuro fazer isso com meus alunos, mesmo na primeira série, o negócio do mensalão [...] eu discuto[...]. Eu acho que é importante a criança, desde pequena, já ter consciência de certas coisas, para depois não ser levada, assim, como acaba sendo hoje em dia.

Percebe-se, a partir da manifestação de Vanessa, que ela se expressa a partir de um conceito restrito de política, identificando-a, em certo sentido, com "luta pelo poder" ou com seu sentido formal e específico envolvendo o funcionamento dos poderes da república. Escapa-Ihe a compreensão da política em seu sentido amplo de convivência

2 Para manter o sigilo das fontes, os nomes das pessoas entrevistadas são fictícios. 
entre sujeitos, individuais ou coletivos. Não percebe que as crianças de sete ou oito anos não têm suficiente discernimento para discutir a política nacional, tomando posição diante de atos governamentais, judiciários ou legislativos. Deixa escapar, assim, a oportunidade de proporcionar aos educandos condições de entrar em contato com a política e, mais do que isso, com a política em sua forma democrática, ou seja, como convivência pacifica entre indivíduos e grupos que "se afirmam como sujeitos".

Nesse sentido mais amplo e rigoroso de democracia, passivel de envolver todos os atos e momentos da vida em sociedade, é que seria possivel oferecer condições de aprendizado e prática da democracia a crianças na idade dos alunos de Vanessa. Não seria, no entanto, na forma meramente verbal, pelo acréscimo de conhecimentos nas listas das disciplinas tradicionais, porque não se trata de "doutrinar" as crianças, mas de dar-Ihes condições de aprender democracia, agindo democraticamente. Nesse período de formação de suas personalidades, não são preponderantemente os discursos, mas as condutas, os comportamentos, os modos de ser e de agir que enriquecem a personalidade das crianças e criam nelas valores democráticos. Aqui, mais do que nunca, a forma se faz conteúdo, na relação dialógica entre todos que participam da situação de ensino; na discussão e na tomada de decisões nas pequenas coisas do dia a dia; na convivência em grupos de estudo, de brincadeiras e de trabalho; no desenvolvimento da autonomia e da autodisciplina, no comportamento de aceitação do outro; na valorização da paz; no exercício do companheirismo etc. etc.

Ao falar sobre "fatores sociológicos que perturbam o processo de valoração na sociedade moderna", Karl Mannheim (1967, p. 37-38, grifo nosso) afirma que,

para criar um cidadão obediente à lei cuja obediência não se baseexclusivamente na cegueira da aceitação e do hábito, devemos reeducar o homem integral. As pessoas que se acham condicionadas a aceitar cegamente valores, por meio de obediência, imitação ou de sugestão emocional, dificilmente serão capazes de se haver com valores cujo apelo à razão e cujos princípios subjacentes podem e devem ser discutidos. Ainda não nos demos completamente conta de quão tremenda seria a reforma da educação necessária para fazer funcionar uma sociedade democrática, baseada na apreciação consciente dos valores. [...].

Mais adiante, o mesmo autor, ao referir-se ao choque entre as valorações e os métodos de educação em vigor, afirma:

[...] Não se pode criar um novo mundo moral alicerçado sobretudo em apreciação dos valores racionais, isto é, valores cuja função social e psicológica seja inteligivel, e ao 
mesmo tempo conservar um sistema educacional que em suas técnicas essenciais aja por meio da criação de inibições e procure impedir o desenvolvimento da capacidade crítica. [...] (MANNHEIM, 1967, p. 38-39).

Andreia, professora da terceira série, parece mais próxima de uma abordagem correta do problema quando procura adequá-lo em termos de conduta para com o outro. Diante da pergunta sobre como "preparar para a vida", diz que precisa ensinar a cidadania. Quando se põe a explicar o que é isso diz: "Eu ser um cidadão, eu gostar do outro, eu me identificar com o outro, eu respeitar o outro. Isso é essencial." Mas, a seguir, ao se reportar aos valores como conteúdos do ensino, parece adotar uma concepção que tem mais a ver com disciplina e moralização:

Nós estamos com uma sociedade agressiva, cheia de problemas. Eu acho (isso eu acho, não tenho certeza ainda), eu acho que é pela falta do limite [...] que os pais não estão dando mais; a falta de tempo que eles acham que eles não têm mais pro seu filho [...] É que eles não entendem o caminho; então, isso que eu falo que eles estão pondo na escola, essa é a parte que a escola tem que fazer que eu acho que o pai também tem que fazer [...] [a questão dos valores].

É comum encontrar-se no discurso dos educadores escolares um apelo para a imposição de "limites", em lugar da criação de condutas democráticas, e a atribuição à família de um papel civilizador que, de saída, já se denuncia que ela não tem condições de desempenhar. A escola, assim, é vista como tendo que exercer um papel civilizatório, passando uma moral que as populações não teriam. Em suma, parece que, em geral, quando se fala que a escola tem que dar cidadania aos educandos, se está pensando apenas em mais conhecimentos e conhecimentos mais adequados aos tempos modernos, com ênfase nos valores. Nada se menciona do direito à cultura integral, essa sim capaz de formar personalidades consentâneas com o conceito de cidadania.

Embora não pareça ser a regra, é possivel encontrar entre os educadores escolares quem perceba o caráter pouco atrativo do currículo e da didática da escola e se preocupe com isso e com a necessidade de mudança. Das pessoas entrevistadas, Vera Sanches, a coordenadora pedagógica, foi quem mais demonstrou essa percepção. Pergunto-Ihe o que se deve fazer para tornar a escola interessante para o aluno e ela responde, como num desabafo:

A escola do dia a dia é uma escola chata. Tem que transformar numa escola prazerosa. De repente, você tirar um pouco da sua aula conteudista, fazer uma competição de jogos, fazer uma competição entre pais e filhos, criar uma atividade extraescola, extraclasse, extracurrículo, extratudo, fazer alguma 
mágica, fazer alguma coisa, porque a escola nossa é chata, sim; ela é conteudista, sim; e a gente tem normas chatas, sim [...] e teria que, pelo menos uma vez, um dia, colocar isso tudo de lado e transformar a escola numa escola prazerosa, uma escola lúdica, numa "contação" de história [...]. Chutar mesmo, como dizem aí vulgarmente, o pauzinho da barraca e transformar numa escola gostosa, num grande circo [...]

A coordenadora fala em grandes transformações, em mágica e, embora não fundamente tecnicamente a mudança, sente que precisa mudar; porque é uma escola "chata", quer uma escola "prazerosa". É ousada. Não sabe arrolar as razões por que a escola deve mudar para ser eficaz, o que evidencia a falta de suporte técnico-pedagógico do sistema de ensino para proporcionar aos trabalhadores da educação aptidão e confiança para sugerir e implementar qualquer tipo de mudança no campo didático ou curricular. De qualquer forma, o importante no discurso de Vera Sanches é que ela escapa do senso comum, o qual relaciona (quando relaciona) o prazer em aprender com o "conteúdo" do ensino, ou seja, com o tipo e a quantidade de conhecimento disponiveis. Segundo essa concepção, enriquecer o currículo é dar novos conhecimentos. Vera Sanches percebe que é isso também, mas não é apenas isso. A situação exige uma mudança mais profunda que toca no que se ensina e como se ensina.

Também Raquel, diretora da escola, se preocupa com o caráter enfadonho das atividades escolares. Ela acha que a criança precisa aprender, não apenas a ler e a escrever, mas também a cantar, a dançar, a realizar atividades artísticas etc.

Hoje em dia, a criança tem que aprender a ler e a escrever. Eu gostaria de estar propondo, e quero e vou propor essas outras atividades, mas para que facilite essa compreensão do mundo também, dentro do ler e escrever, questão de atitudes e procedimentos. Mas eu acredito que uma criança que dança, uma criança que pula corda, uma criança que cante, que goste de cantar, ela vai ter interesse também em saber a letra da música [e terá mais interesse].

Sobre o enriquecimento do currículo, Márcia, a vice-diretora, se refere à escola de tempo integral, que existiria em escolas do Estado, que ela considera uma boa ideia, mas que a notícia que ela tem é de que "é uma porcaria", porque a escola não tem estrutura para realizar seus fins.

E o que que eles falam? Que não dá certo, todo mundo reclama, isso é o que eu ouço, que a escola de tempo integral é uma porcaria, e que não dá certo por causa da estrutura. A escola não tem estrutura para estar trabalhando desse jeito. Mas seria muito importante se a gente tivesse estrutura. 
A questão levantada por Márcia é uma das mais importantes nas discussões que se fazem sobre a chamada escola de período integral. Por considerar o tempo diário normalmente utilizado para o ensino insuficiente para uma boa formação do educando, advoga-se a extensão do período diário de escolaridade, julgando que com "período" integral se consiga a "educação" integral. Mas esse raciocínio se baseia em premissas falsas, porque o período de quatro ou cinco horas que a criança passa na escola não é "o único", nem o maior problema que impede uma educação integral. Como temos visto, é mesmo a estrutura da escola, em termos administrativos, curriculares e didáticos, que precisa ser transformada para a educação escolar caminhar nesse sentido. Sem dúvida, a extensão do tempo de escolaridade é um dos aspectos a ser levado em conta. Mas, simplesmente dobrar o período de uma escola ineficiente pode ter o efeito de multiplicar por dois sua ineficiência e o dano que ela causa ao educando (PARO et al., 1988).

Um aspecto curioso relacionado à estrutura didática e curricular de nossa escola fundamental é o fato de que, mesmo com métodos ultrapassados que lhes tolhem a espontaneidade e com currículos pouco significativos para suas vidas, os estudantes ainda são atraídos pela escola. Tenho-me interessado por esse fenômeno em várias pesquisas de campo que tenho feito e sempre se confirma essa hipótese, com muitas referências dos alunos a respeito da falta que sentem da escola nas férias, por exemplo. Também nas várias investigações tenho procurado saber entre os professores e pessoal da escola a respeito da causa dessa atração, e a conclusão que esses depoimentos favorecem é que seu motivo principal é o convívio com os colegas.

Já tratei desse tema em outra obra (PARO, 2000), mas procurei atualizar as informações junto aos entrevistados desta investigação, que em geral confirmaram a hipótese. A exceção foi Vera Sanches, a coordenadora pedagógica. Ela diz que a escola ainda atrai o aluno e "ele vem mesmo". Mas mostrou-se surpresa com a pergunta sobre a razão por que o aluno ainda gosta da escola, apesar de tudo. Ela, que havia reafirmado que a escola é chata, não conseguia dar uma resposta à questão. Pôs-se, então, a levantar algumas razões: a merenda, a Educação Física (que é a aula que ele mais gosta). Diz que a escola é importante porque substitui muita coisa que deveria ser feita em casa. Exemplo disso é a extensão do ensino fundamental para alunos de seis anos, precisamente para dar ao aluno coisas que os pais das famílias pobres não podem dar: iniciação à alfabetização. Ainda sobre a pergunta, Vera Sanches volta a demonstrar sua preocupação e surpresa: "E essa pergunta aqui, olha, eu vou jogar para os meus professores. Porque ninguém tinha pensado. Agora que eu fui pensar, porque aqui na escola, a gente procura mesmo [...]". E continua mencionando o trabalho de uma das professoras que desenvolve atividades variadas e procura realizar uma aula que seja desejada pelos alunos. 0 intrigante, entretanto, não é a surpresa da coordenadora, mas sim o fato de que, mesmo tendo a percepção de que o que as crianças gostam é o relaci-

Ensaio: aval. pol. públ. Educ., Rio de Janeiro, v. 19, n. 72, p. 485-508, jul./set. 2011 
onamento pessoal, o contato e a brincadeira com outras crianças, dificilmente os professores conseguem propor atividades que se voltem para isso, ou seja, não veem a necessidade de o ensino incluir esses elementos em seus métodos e conteúdos, de modo a fazer uma escola mais interessante.

Quem visita nossa escola fundamental com olhos críticos a todo momento se surpreende com as relações e fatos que presencia. Uma das surpresas é constatar como a escola consegue criar nas crianças a ojeriza à própria cultura. Elaine, professora da primeira série, diz que seus alunos não gostam da aula de artes. Ela faz críticas ao modo (formal, tradicional, desinteressante) como a professora dá a disciplina. Não deixa de ser altamente intrigante que as crianças não gostem da aula de artes! Observe-se o que a escola consegue fazer com a cultura, até mesmo com seus conteúdos mais prazerosos, criativos, estimulantes e belos!

Essa falta de interesse pela aula de artes lembra um dos aspectos mais importantes para uma escola que pretenda transmitir, não apenas conhecimentos, mas cultura em seu sentido pleno: trata-se da influência decisiva da capacidade do educador no desempenho de seu papel. Vera Sanches, coordenadora pedagógica, acha que o currículo hoje é muito pobre e que está muito "igualado por baixo". "Eu acho que acaba sendo superficial, eu não transmito cultura para o meu aluno". Mas ela acha que o problema não está no conteúdo, e sim no professor, que precisaria ser "uma pessoa muito, muito, muito, muito culta. Seria o professor porque é o professor que abre, ou que terá de percorrer esse caminho, para estar levando o aluno a ter esse conhecimento."

A preocupação de Vera Sanches parece ter toda procedência, quando se atenta para a realidade de nossos professores. Em primeiro lugar, eles sequer têm condições satisfatórias de acesso a uma cultura mais elaborada. Quando se menciona aos professores a importância da cultura, eles têm alegado que o salário que recebem não permite sequer a eles próprios pagar a assinatura de um jornal ou de uma revista, ou comprar um livro periodicamente, e muito menos a ter acesso a uma peça de teatro ou a um concerto, por exemplo. A verdade é que, em nossa sociedade, os bens e serviços culturais costumam ser muito dispendiosos para o cidadão comum, porque são produzidos em baixa escala, para consumo apenas de poucos privilegiados.

Associado a esse tema está a fraca importância que é dada socialmente a qualquer tipo de refinamento cultural. Para ficar apenas num exemplo, pode-se citar a desvalorização que tem entre nós o exercício da leitura. 0 problema já começa com o ensino de Língua Portuguesa, enfadonho e ineficiente desde a alfabetização até o contato (quando há) com as obras literárias nacionais e internacionais. 0 mal que a escola tem feito à apreciação da leitura é alarmante. As crianças, em vez de adquirirem o hábito de ler e a capacidade de usufruir do direto à literatura (MELLO E SOUZA, 2004), acabam por adquirir resistência à leitura e ficam privadas, quando adultas, desse importante bem 
cultural. Não bastasse isso, os poucos que tiveram a felicidade de uma formação que os levou ao gosto pela leitura acabam por ser permanentemente tolhidos em suas tentativas de ler em lugares públicos, por exemplo. Dificilmente se encontra uma sala de espera de escritório, de aeroporto, de consultório médico, de repartição pública, ou de qualquer local em que se tenha de aguardar para ser atendido que não tenha um televisor ou um rádio ligados num volume que impede o saudável exercício da leitura. 0 fato de não ter havido ainda nenhum movimento (pelo menos que seja de conhecimento público) que reclame contra essa restrição ao direito de ler, parece bem um indicativo do exíguo número de pessoas que tentam dele usufruir nessas situações.

Mas, além das más condições de trabalho do professor e do baixo valor atribuído ao aspecto cultural, há um terceiro fator decisivo a dificultar a transmissão da cultura no ensino fundamental. Como deu a entender a diretora da escola, convém ser culto para transmitir cultura. Acontece que os professores e demais adultos com os quais a criança tem contato (inclusive seus familiares) são frutos de uma escola tão carente de cultura quanto a de hoje. Por isso, convém não ignorar que qualquer solução para a formação cultural das crianças de hoje precisa incluir o acesso à cultura também dos adultos, especialmente seus professores.

Há professores que sequer veem a necessidade de alguma mudança substancial na estrutura curricular, quando muito sugerindo alguma atividade ou conteúdo no currículo existente. Marilda, professora da quarta série, por exemplo, diz que não mudaria o conteúdo, contanto que se intercalasse outras atividades aos conteúdos comuns. 0 que precisa é sair da rotina, diz ela: ter muitas atividades.

Outro fenômeno que serve para dificultar o desenvolvimento de um currículo mais rico é a atitude de certo modo "conteudista" dos pais. Vanessa, professora da segunda série, diz que nas duas séries iniciais, agora, só há Língua Portuguesa e Matemática. Ela concorda com isso, porque acha ambas fundamentais. Diz que os outros conteúdos podem ser trabalhados dentro dessas duas disciplinas. Perguntada se o currículo não deveria contemplar também música, dança, etc., Vanessa concorda (na verdade, se dá conta disso). Diz que procura dar música, jogos etc., mas que os pais não concordam com isso. "Na verdade é uma atividade de leitura, mas os pais acham que eu estou dando brincadeira. Eles não gostam muito. Eu vejo que eles preferem uma professora que encha o caderno."

Às vezes, o professor, quando convidado a refletir sobre o currículo atual, acaba se dando conta de suas deficiências e, numa atitude defensiva, apresenta justificativas ou desculpas para o fato de não estar desenvolvendo determinados conteúdos. Elaine, professora da primeira série, concorda que o currículo deve mudar. Diz que há a proposta de currículo, "mas você tem que estar seguindo, ali, aquele roteiro. Eu acho que isso é muito ruim." Diz que "as crianças vêm com tantas falas e não se pode desenvolver, porque tem que seguir o programa". Na verdade, um programa muito 
rígido impõe dificuldades à criatividade e a uma maior abertura para conteúdos culturais mais elaborados e mais diversificados, mas a pergunta que se faz é se esse é o único empecilho. Parece que não. Na verdade não é só porque "não se pode" que a cultura não é privilegiada, mas também porque o professor não sabe o que fazer.

\section{Síntese e conclusões}

0 escopo deste artigo foi o de trazer ao campo das discussões a questão do currículo do ensino fundamental. Não, todavia, do ponto de vista estritamente técnico, que privilegia a seleção, ordenação e relacionamento das disciplinas tradicionais, em seus conteúdos pautados na transmissão de conhecimentos; mas de modo a questionar a estrutura curricular em seus próprios fundamentos, como propósito de oferecer subsídios teóricos e argumentativos àqueles que discutem, elaboram e implementam políticas públicas para a educação. Espera-se também que as ponderações apresentadas contribuam para uma melhor reflexão sobre o real sentido da qualidade do ensino e sobre a necessidade da elaboração e adoção de instrumentos mais adequados para sua avaliação, tanto em nível de sistema quanto no âmbito das unidades escolares.

Vimos, então, que, com relação à discussão do redimensionamento do currículo da escola fundamental, de modo a abarcar a cultura em suas múltiplas dimensões, 0 suposto básico é que, para a formação do estudante desse nivel de ensino não bastam os conteúdos de conhecimentos e informações que compõem as disciplinas escolares tradicionais, embora tais conteúdos não devam, em nenhuma hipótese, sofrer restrições. 0 que é urgente é que conteúdos importantíssimos, que hoje são minimizados ou completamente ignorados, ganhem o seu lugar de importância no currículo.

Nenhuma "sociedade do conhecimento", como insiste o jargão acadêmico, sobrevive apenas com conhecimentos. É a cultura em seu sentido pleno, que abarca tudo o que é produzido historicamente pelos seres humanos, que precisa ser considerada como matéria-prima do currículo quando o que está em jogo é o atendimento do direito do cidadão, numa sociedade democrática. Por isso, conteúdos relacionados à arte, à ética, à política, ao cuidado pessoal, ao uso do corpo etc. devem ser incluídos no rol de elementos culturais componentes do ensino fundamental.

Tendo em vista esses conteúdos bem como o avanço teórico-prático da Didática no que se refere à necessária consideração do educando como sujeito no processo pedagógico, a primeira questão curricular de importância é seu relacionamento com a estrutura didática da escola. A multiplicidade e a complexidade dos elementos culturais não admitem, especialmente na fase de desenvolvimento biopsíquico e social da criança e do jovem, sua apropriação na forma "simplória" da mera passagem de conhecimentos. Por outro lado, são esses "novos" conteúdos - pelo envolvimento com a subjetividade do "aprendente" que eles exigem e propiciam - que contribuirão para que a apropriação dos conhecimentos tradicionais (agora sim) possam ser apreendidos com mais eficácia. 
A estreiteza do conceito de educação que a relaciona apenas à transmissão de conhecimentos e informações tem reduzido a apenas isso a compreensão do direito constitucional à educação, deixando na sombra o verdadeiro direito à humanização do cidadão que é seu direito à cultura. A negação desse direito, que na sociedade em geral se concretiza na falta do acesso aos bens culturais de vastas camadas da população, começa na escola, pela recusa, quer da fruição dessa cultura, quer do oferecimento dos meios intelectuais necessários para seu pleno usufruto.

Aspecto de destaque na discussão do direito do cidadão à cultura é o oferecimento de uma educação que concorra para a construção daquilo que se poderia chamar de personalidade democrática do indivíduo. A esse respeito, assim como a educação não se faz crítica apenas a partir de conhecimentos críticos, também a democracia não se aprende nem passa a compor a personalidade, sem que seja exercitada na prática da vida cotidiana. Em vista disso e considerando a importância do período em que se frequenta o ensino fundamental na construção da personalidade, é preciso extremo cuidado na formação dos professores, não esquecendo que é preciso ser culto para transmitir cultura, é preciso ser democrático para formar personalidades democráticas.

0 cuidado em proporcionar educadores capazes para uma educação de qualidade precisa considerar que o que, a rigor, mais influiu na personalidade do professor foi uma escola fundamental tão carente de cultura quanto a de hoje. Uma verdade - que se suspeita secular - é que os professores de determinada geração reproduzem com seus alunos o que seus mestres fizeram com eles no passado. Para quebrar essa tradição, e independentemente de medidas que se venham tomar com relação à formação de professores em nivel superior, convém dedicar todo esforço na formação em serviço das centenas de milhares de professores que já estão nas escolas, formando (?) as novas gerações. Essa parece ser uma forma efetiva de melhorar a escola de hoje e, ao mesmo tempo, contribuir para a formação do professor de amanhã.

Em suma, as reflexões sobre a estrutura curricular da escola fundamental corrobora considerações sobre os demais aspectos da estrutura total da escola feitas no relatório geral da pesquisa (PARO, 2010): a concepção global da escola precisa mudar se quisermos que ela seja adequada a uma educação comprometida com a formação de sujeitos humano-históricos, portadores de cultura e que usufruem dos bens culturais como direito universal. Em vista disso, as mudanças no currículo do ensino fundamental devem se articular com as demais transformações que nossa tradicional escola exige: na estrutura administrativa, na estrutura didática, no trabalho docente, na atividade discente e na participação da comunidade. 0 processo pedagógico escolar, à luz dos avanços científicos na área da Pedagogia, e de acordo com sua especificidade humano-social, precisa ser contemplado com tempos e espaços que favoreçam seu pleno desenvolvimento e que garantam sua realização como prática democrática enriquecedora de personalidades cidadãs. 


\section{Referências}

CÂNDIDO, A. A estrutura da escola. In: PEREIRA, L; FORACCHI, M. M. Educação e sociedade: leituras de sociologia da educação. 6. ed. São Paulo: Nacional, 1974. p. 107-128.

FRANCA, L. O método pedagógico dos jesuitas: o Ratio Studiorum. Rio de Janeiro: Agir, 1952.

FREIRE, P. Pedagogia do oprimido. 2. ed. Rio de Janeiro: Paz e Terra, 1975.

GUDSDORF, G. Professores para quê?: para uma pedagogia da pedagogia. São Paulo: Martins Fontes, 1987.

HERBART, J. F. Pedagogia geral. Lisboa: Fundação Calouste Gulbenkian, 2003.

LEÃO, A. C. Introdução à administração escolar: para as escolas de professores dos institutos de educação, universidades e faculdades de filosofia, ciências e letras. 3. ed. São Paulo: Nacional, 1953.

LOBROT, M. A favor ou contra a autoridade. Rio de Janeiro: Francisco Alves, 1977.

LOURENÇO FILHO, M. B. Introdução ao estudo da escola nova: bases, sistemas e diretrizes da Pedagogia Contemporânea. 14. ed. Rio de Janeiro: Eduerj: Conselho Federal de Psicologia, 2002.

MANNHEIM, K. Diagnóstico de nosso tempo. Rio de Janeiro: Zahar, 1967.

MELLO E SOUZA, A. C. 0 direito à literatura. In: CARVALHO, J. S. (Org.).

Educação, cidadania e direitos humanos. Petrópolis: Vozes, 2004. p. 130-158.

PARO, V. H. Estrutura da escola e educação como prática democrática. São Paulo: Feusp, 2010. Relatório de Pesquisa.

. Gestão escolar, democracia e qualidade do ensino. São Paulo: Ática, 2007. - Implicações do caráter político da educação para a administração da escola pública. Educação e Pesquisa, São Paulo, v. 28, n. 2, p. 11-23, jul./dez. 2002.

. Qualidade do ensino: a contribuição dos pais. São Paulo: Xamã, 2000.

. Reprovação escolar: renúncia à educação. 2. ed. São Paulo: Xamã, 2003.

PARO, V. H. et al. Escola de tempo integral: desafio para o ensino público. São Paulo: Cortez, 1988.

WHITEHEAD, A. N. Fins da educação e outros ensaios. São Paulo: Nacional, 1969.

Recebido em: 01/04/2011

Aceito para publicação em: 28/06/2011 